\title{
DESIGN AND THERMAL EVALUATION OF SHELL AND HELICAL COIL HEAT EXCHANGER
}

\author{
Amitkumar S. Puttewar', A.M. Andhare ${ }^{2}$ \\ ${ }^{1}$ Research Scholar, Department of Mechanical Engineering, Shri Ramdeobaba College of Engg. and Mgmt, Nagpur, \\ Maharashtra, India \\ ${ }^{2}$ Assistant Professor, Department of Mechanical Engineering, Shri Ramdeobaba College of Engg. and Mgmt, Nagpur, \\ Maharashtra, India
}

\begin{abstract}
Heat exchangers are the important engineering equipments used for transferring heat from one fluid to another. Heat exchangers are widely used in various kinds of application such as power plants, nuclear reactors, refrigeration and air-conditioning systems, heat recovery systems, petrochemical, mechanical, biomedical industries. Helical coil heat exchangers are gaining wide importance now-a-days because it can give high heat transfer coefficient in small footprint of surface area. This paper focuses on the designing of shell and helical coil heat exchanger and its thermal evaluation with counter flow configuration. The thermal analysis is carried out considering the various parameters such as flow rate of cold water, flow rate of hot water, temperature, effectiveness and overall heat transfer coefficient.
\end{abstract}

Keywords - Helical coil heat exchanger, Counter flow, Flow rate, effectiveness, heat transfer coefficient etc.

\section{INTRODUCTION}

In most Industries, the designing and thermal evaluation of heat exchangers is generally carried out in order to reduce cost, material and energy and to obtain maximum heat transfer. The main challenge in heat exchanger design is to make it compact and to get maximum heat transfer in minimum space. The passive enhancement technique using coiled tube has significant ability in enhancing heat transfer by developing secondary flow in the coil. Due to enhanced heat transfer the study of flow and heat transfer in helical coil tube is of vital importance. The first attempt has been made by Dean [1] to describe mathematically the flow in a coiled tube. A first approximation of the steady motion of incompressible fluid flowing through a coiled pipe with a circular cross-section is considered in his analysis. It was observed that the reduction in the rate of flow due to curvature depends on a single variable, $\mathrm{K}$, which is equal to 2(Re) $2 r / R$, for low velocities and small $r / R$ ratio. Dravid et al. [2] shown that the intensity of secondary flow developed in the tube is the function of tube diameter $\left(D_{i}\right)$ and coil diameter $\left(D_{c}\right)$. Naphon [3] investigated the thermal performance and pressure drop of a shell and helical coiled tube heat exchanger with and without helical crimped fins. Naphon et al. [4] summarized the phenomenon of heat transfer and flow characteristics of single-phase and twophase flow in curved tubes including helically coiled tubes and spirally coiled tubes. Kirpikov [5] studied the heat transfer in helically coil heat exchanger considering coil curvature and using wall to bulk temperature difference and deduced a correlation for it. White [6] has continued the study of Dean for the laminar flow of fluids with different viscosities through curved pipes with different curvature ratios $(\delta)$. The result shows that the onset of turbulence did not depend on the value of the Re or the De. He concluded that the flow in curved pipes is more stable than flow in straight pipes. White also studied the resistance to flow as a function of De and Re. There was no difference in flow resistance compared to a straight pipe for values of De less than 11.6. Seban and McLaughlin [7] experimentally studied the heat transfer for oil laminar flow and water turbulent flow in uniformly heated HCTs $(0.0096 \leq \delta \leq 0.0588)$. They concluded that the outer periphery has higher local Nusselt number than the inner with both being substantially higher than values for a straight pipe under the same conditions. Prabhanjan et al. [8] studied the heat transfer studies of a helical coil immersed in a water bath. An analytical and experimental study has carried out by Shokouhmand et al.[11] done experimental investigation on shell and coil tube heat exchanger using Wilson plot technique and inner heat transfer coefficient so obtained are found in good agreement. Pandey et al. [12] study hydrodynamic characteristics of single phase fluid flow inside a vertical helically coiled tube of curvature ratio 0.012 is investigated experimentally for the laminar flow regime for water and nitrobenzene. Purandare et al. [13] had done the comparative analysis of various correlations given by different researchers. The overall effects of various parameters on heat transfer coefficient involved in correlations are studied.

\section{NOMENCLATURES}

$\begin{array}{ll}\text { A } & \text { surface area of coiled tube, } \mathrm{m}^{2} \\ \mathrm{~b} & \text { coil pitch, } \mathrm{m} \\ \mathrm{C}_{1}, \mathrm{C}_{2} & \text { constants } \\ \mathrm{Pr} & \text { Prandtl number, }=\mu \mathrm{C}_{\mathrm{P}} / \mathrm{k} \\ \mathrm{D}_{\mathrm{c}} & \text { coil Diameter, } \mathrm{m} \\ \mathrm{d} & \text { coiled tube diameter, } \mathrm{m} \\ \mathrm{D} & \text { shell diameter, } \mathrm{m}\end{array}$


$\mathrm{D}_{\mathrm{h}} \quad$ shell-side hydraulic diameter, $\mathrm{m}$

f friction factor

$\mathrm{h} \quad$ averaged convective heat transfer coefficient, $\mathrm{W} / \mathrm{m}^{2} \mathrm{~K}$

$\mathrm{k}$ thermal conductivity, $\mathrm{W} / \mathrm{m}^{2} \mathrm{~K}$

$\mathrm{L} \quad$ heat exchanger length, $\mathrm{m}$

$\dot{m} \quad$ mass flow rate, $\mathrm{kg} / \mathrm{s}$

m slope

$\mathrm{n} \quad$ exponent in Eq. (1)

$\mathrm{N}$ number of turns

$\mathrm{Nu} \quad$ Nusselt number

P pressure

Q Heat Transfer rate, W

$\mathrm{R} \quad$ Resistance

$\mathrm{R}_{\mathrm{c}} \quad$ curvature radius, $\mathrm{m}$

$\mathrm{Re} \quad$ Reynolds number

$\mathrm{t} \quad$ thickness of tube and shell, $\mathrm{m}$

$\mathrm{T}$ temperature, ${ }^{\circ} \mathrm{C}$

$\mathrm{U} \quad$ overall heat transfer coefficient, $\mathrm{W} / \mathrm{m}^{2} \mathrm{~K}$

$\mathrm{V} \quad$ fluid average velocity, $\mathrm{m} / \mathrm{s}$

\section{Greek letters}

$\begin{array}{ll}\delta & \text { curvature ratio } \\ \gamma & \text { dimensionless pitch } \\ \mu & \text { viscosity, } \mathrm{N}-\mathrm{s}_{\mathrm{m}} \mathrm{m}^{2} \\ \rho & \text { density, } \mathrm{kg} / \mathrm{m}^{3} \\ \Delta & \text { delta }\end{array}$

\section{Subscripts}

i inside condition

o outside condition

h hot fluid

c cold fluid

avg average

min minimum

$\max \quad$ maximum

ov overall

\section{GEOMETRY OF HELICAL COILS}

The schematic diagram shows dimensional and operating parameters of helical coil heat exchanger.

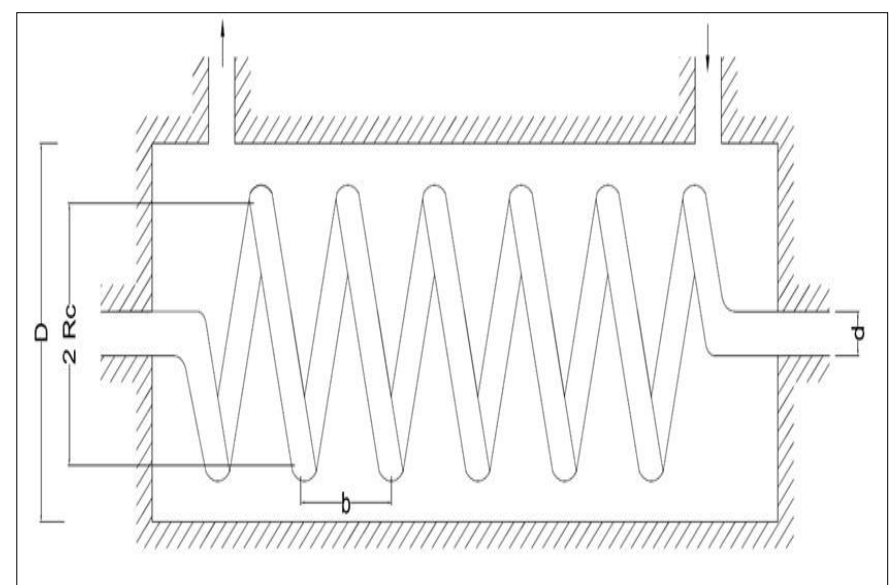

Fig-1: Schematic of shell and helical coil

\section{PARAMETERS OF HELICAL COILS}

Table-1: Dimensional parameters of Helical coil.

\begin{tabular}{|l|l|l|}
\hline $\begin{array}{l}\text { Sr. } \\
\text { No }\end{array}$ & Dimensional Parameters & Dimensions \\
\hline 1. & $\begin{array}{l}\text { Outer diameter of Mild Steel } \\
\text { cylinder }\left(\mathrm{D}_{\mathrm{o}}\right)\end{array}$ & $0.1524 \mathrm{~m}$ \\
\hline 2. & $\begin{array}{l}\text { Inner diameter of Mild Steel } \\
\text { cylinder }\left(\mathrm{D}_{\mathrm{i}}\right)\end{array}$ & $0.1494 \mathrm{~m}$ \\
\hline 3. & Thickness of Shell $(\mathrm{t})$ & $3 \mathrm{~mm}$ \\
\hline 4. & Outer diameter of tube $\left(\mathrm{d}_{\mathrm{o}}\right)$ & $0.0127 \mathrm{~m}$ \\
\hline 5. & Inner diameter of tube $\left(\mathrm{d}_{\mathrm{i}}\right)$ & $0.0117 \mathrm{~m}$ \\
\hline 6. & Thickness of tube $(\mathrm{t})$ & $1 \mathrm{~mm}$ \\
\hline 7. & Curvature Radius $\left(\mathrm{R}_{\mathrm{c}}\right)$ & $0.045 \mathrm{~m}$ \\
\hline
\end{tabular}

Table-2: Operating parameters range of helical coil heat

\begin{tabular}{|l|l|l|}
\hline \multicolumn{4}{|c|}{ exchanger. } \\
\hline Parameter & Cold water & Hot water \\
\hline Initial temperature $\left({ }^{\circ} \mathrm{C}\right)$ & 22.4 & $0.111 \mathrm{~kg} / \mathrm{s}$ \\
\hline Outlet Temperature $\left({ }^{\circ} \mathrm{C}\right)$ & 39.5 & 48.8 \\
\hline
\end{tabular}

Table-3: Properties of Hot and cold fluid of helical coil heat exchanger.

\begin{tabular}{|l|l|l|}
\hline Properties & Cold water & Hot water \\
\hline $\begin{array}{l}\text { Specific heat }(\mathrm{Cp}) \\
\left(\mathrm{J} / \mathrm{Kg}{ }^{\circ} \mathrm{C}\right)\end{array}$ & 4178 & 4179.2 \\
\hline Viscosity $(\mu)\left(\mathrm{N}-\mathrm{s} / \mathrm{m}^{2}\right)$ & 0.000753 & 0.000620 \\
\hline Density $(\rho)\left(\mathrm{kg} / \mathrm{m}^{3}\right)$ & 994.629 & 990.688 \\
\hline $\begin{array}{l}\text { Thermal conductivity } \\
(\mathrm{k}) \mathrm{W} / \mathrm{m}^{2} \mathrm{~K}\end{array}$ & 0.6216 & 0.6352 \\
\hline Prandtl No. (Pr) & 5.06 & 4.08 \\
\hline
\end{tabular}

The properties are taken at mean bulk temperature.

\section{EXPERIMENTAL PROCEDURE}

The schematic diagram of the experimental set up is as shown in Fig.2. The experimental set up consists of a shell in which the helical coil copper tube is placed through which hot water is made to flow with the help of a centrifugal pump. To ensure maximum heat transfer the copper helical coil is fully immersed in the cold water flowing through the shell, the inlet and outlet are so placed as shown in Fig. 1.The shell is well insulated so as to avoid the heat loss to the surrounding. The main components in the set up include centrifugal pump, heating element, cold water storage tank and hot water storage tank. The heat exchanger which includes the helical copper tube and insulated shell is perfectly sealed so as to avoid the leakage of hot water flowing through tube and cold water flowing through shell in a counter flow manner. 


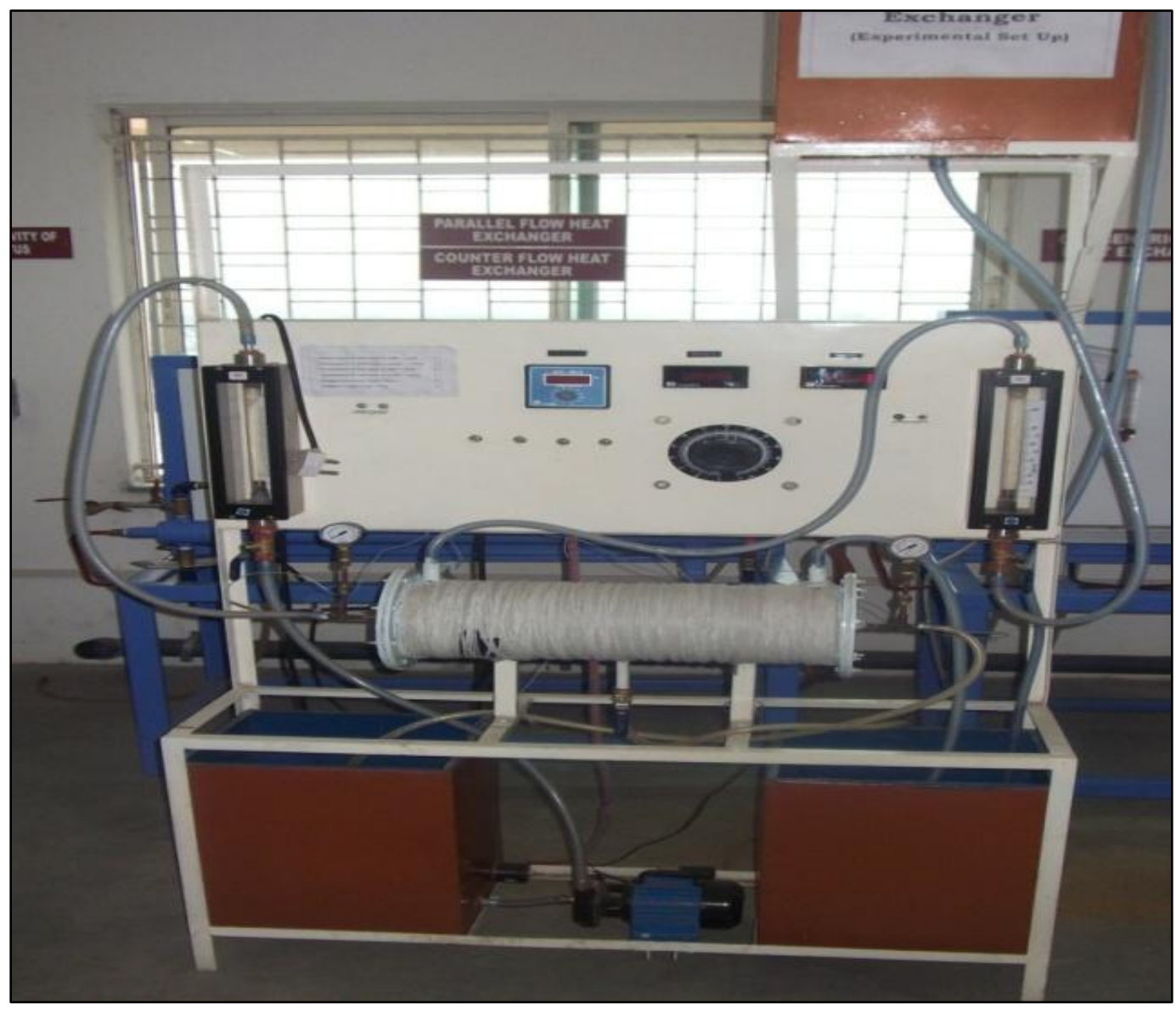

Fig-2: Experimental Setup

The water in the storage tank is heated using a heating element, as the water reaches to a prescribed temperature. The centrifugal pump circulates the hot water through the helical coil. The ball valves are used to control the flow rate of hot and cold water. A calibrated rotameter was used to measure the shell side cold water flow rate while for the tube side hot water flow rate a calibrated vane type flow meter is used and data was recorded using a data logger system. The inlet and outlet temperatures of hot and cold water were recorded using calibrated LM 35 temperature sensor through the data logger system. Pressure gauges were used to measure the pressure loss in the helical coil tube. The tube and shell side thermo-physical properties of water were assessed at their mean temperatures.

\section{DESIGN PROCEDURE FOR HELICAL COIL HEAT EXCHANGER}

The analysis of the helical coil heat exchanger is carried out through following procedure [9][10]:

\section{Step 1:}

Length of coil needed $(\mathrm{L})=\pi \times \mathrm{D}_{\mathrm{c}} \times N$

$\mathrm{D}_{\mathrm{c}}=0.09 \mathrm{~m}$

$\mathrm{N}=18$

On Substituting L $=5.089 \mathrm{~m}$

\section{Step 2:}

Shell side equivalent diameter or Hydraulic diameter

$$
D_{h}=\frac{D_{o}{ }^{2}-\pi D_{c} d_{o}{ }^{2} \gamma^{-1}}{D_{o}+\pi D_{c} d_{o} \gamma^{-1}}
$$

Here,

$\mathrm{D}_{\mathrm{o}}=0.1524 \mathrm{~m}$

$\mathrm{D}_{\mathrm{c}}=0.09 \mathrm{~m}$

$\mathrm{d}_{\mathrm{o}}=0.0127 \mathrm{~m}$

$\gamma=0.0455$

On substituting the values

$\mathrm{D}_{\mathrm{h}}=0.1078 \mathrm{~m}$

Step 3:

Calculating Curvature Ratio

$\delta=\frac{\mathrm{d}_{\mathrm{i}}}{\mathrm{D}_{\mathrm{c}}}$

$\delta=\frac{0.0117}{0.09}$

$=0.13$ 
Step 4:

Calculating Pitch Ratio

$\gamma=\frac{\mathrm{b}}{\pi \mathrm{D}_{\mathrm{c}}}$

$\gamma=\frac{0.018}{\pi \times 0.09}$

$=0.063654$

\section{Step 5:}

Heat carried by Hot water,

$\mathrm{Q}_{\mathrm{h}}=\dot{m}_{\mathrm{h}} \times \mathrm{C}_{\mathrm{ph}} \times \Delta \mathrm{T}_{\mathrm{h}}$

$=2.22 / 60 \times 4179.2 \times(48.8-36)$

$=1979.2691 \mathrm{~W}$

Heat carried by cold water,

$\mathrm{Q}_{\mathrm{c}}=\dot{m}_{\mathrm{c}} \times \mathrm{C}_{\mathrm{pc}} \times \Delta \mathrm{T}_{\mathrm{c}}$

$=0.86 / 60 \times 4178 \times(37.1-22.4)$

$=880.3046 \mathrm{~W}$

The average of two readings $\mathrm{Q}_{\mathrm{avg}}$,

$\mathrm{Q}_{\mathrm{avg}}=\left(\mathrm{Q}_{\mathrm{h}}+\mathrm{Q}_{\mathrm{c}}\right) / 2$

$=(1979.2691+880.3046) / 2$

$=1429.786 \mathrm{~W}$

$\mathrm{Q}_{\max }=\dot{m}_{\min } \mathrm{x} C \mathrm{p}_{\min } \mathrm{x}\left(\mathrm{T}_{\mathrm{hi}}-\mathrm{Tc}_{\mathrm{i}}\right)$

$=(0.86 / 60) \times 4178 \times(48.8-22.4)$

$=1580.955 \mathrm{~W}$

\section{Step 6:}

Heat Exchanger effectiveness

Effectiveness $(\epsilon)=\left(\mathrm{Q}_{\text {avg }} / \mathrm{Q}_{\max }\right)$

$=(1429.786 / 1580.955)$

$=0.904$

\section{Step 7:}

Log mean temperature difference (LMTD)

$$
\begin{aligned}
& \text { LMTD }=\frac{\left(\mathrm{Th}_{\mathrm{i}}-\mathrm{Tc}_{\mathrm{o}}\right)-\left(\mathrm{Th}_{\mathrm{o}}-\mathrm{Tc}_{\mathrm{i}}\right)}{\ln \left(\frac{\mathrm{Th}_{\mathrm{i}}-\mathrm{Tc}_{\mathrm{o}}}{\mathrm{Th}_{\mathrm{o}}-\mathrm{Tc}_{\mathrm{i}}}\right)} \\
& \text { LMTD }=\frac{(48.8-37.1)-(36-22.4)}{\ln \left(\frac{48.8-37.1}{36-22.4}\right)} \\
& \text { LMTD }=12.6261^{\circ} \mathrm{C}
\end{aligned}
$$

\section{Step 8:}

Overall heat transfer coefficient $\left(\mathrm{U}_{\mathrm{o}}\right)$,

The outer surface area of heat exchanger

$\mathrm{A}_{\mathrm{o}}=\pi \mathrm{d}_{\mathrm{o}} \mathrm{L}$

$=\pi \times 0.0127 \times 5.715$

$=0.228 \mathrm{~m}^{2}$

$\mathrm{U}_{\mathrm{o}}=\frac{\mathrm{Q}_{\mathrm{avg}}}{\mathrm{A}_{\mathrm{o}} \text { LMTD }}$

$\mathrm{U}_{\mathrm{o}}=\frac{1429.786}{0.228 \times 12.6261}$

$\mathrm{U}_{\mathrm{o}}=496.6659 \mathrm{~W} / \mathrm{m}^{2} \mathrm{~K}$

\section{Step 9:}

Plotting Wilson Plot [17][18]

$\dot{m}_{\mathrm{h}}=\rho_{\mathrm{h}} \times \mathrm{A}_{\mathrm{c}} \times \mathrm{V}_{\mathrm{i}}$

$\mathrm{A}_{\mathrm{c}}=(\pi / 4) \times \mathrm{d}_{\mathrm{i}}^{2}$

$=(\pi / 4) \times 0.0117^{2}$

$=0.000108 \mathrm{~m}^{2}$

$\mathrm{V}_{\mathrm{i}}=(2.22 / 60) / 990.688 \times 0.000108$

$=0.347334 \mathrm{~m} / \mathrm{s}$

Now Wilson plot is plotted as follows

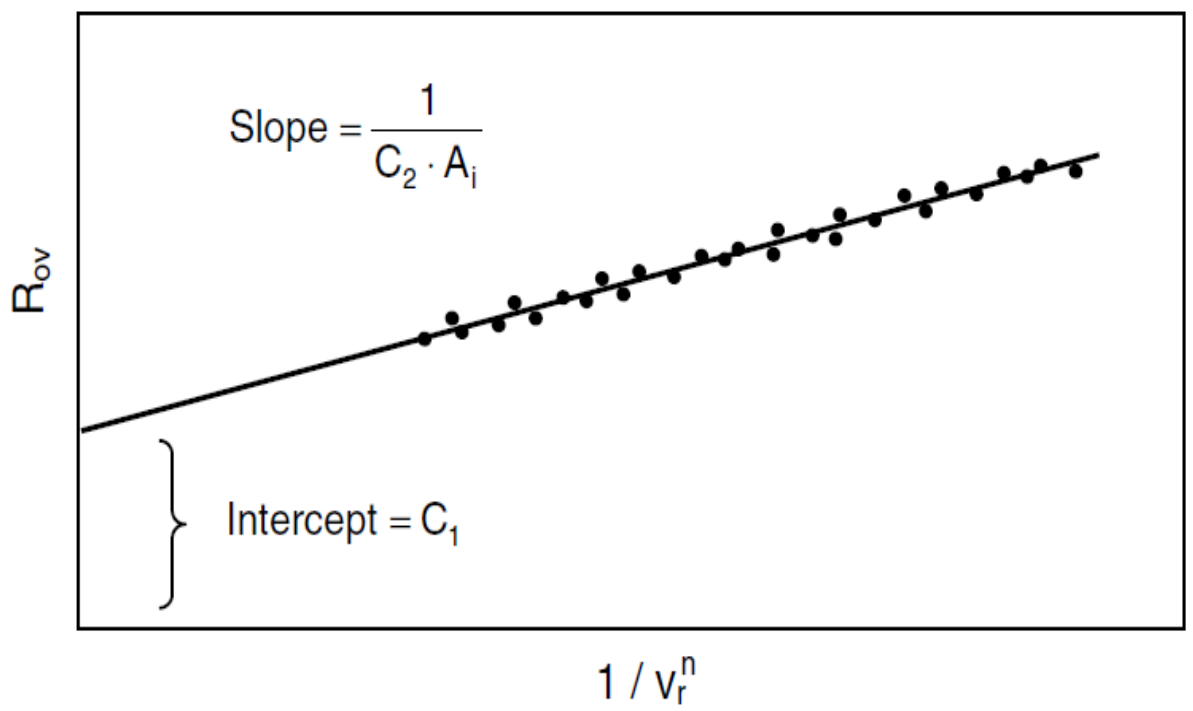

Fig-3: Wilson Plot 
Here, $R_{o v}=1 / U_{0} A_{0}$

$\mathrm{V}_{\mathrm{r}}=\mathrm{V}_{\mathrm{i}}=$ Velocity of hot fluid inside tube.

$\mathrm{n}=$ exponent which is approx. 0.8 .

Now the graph is plotted between the $V_{i}$ and $R_{o v}$ and the best fit is obtained such that $y=m x+c$.

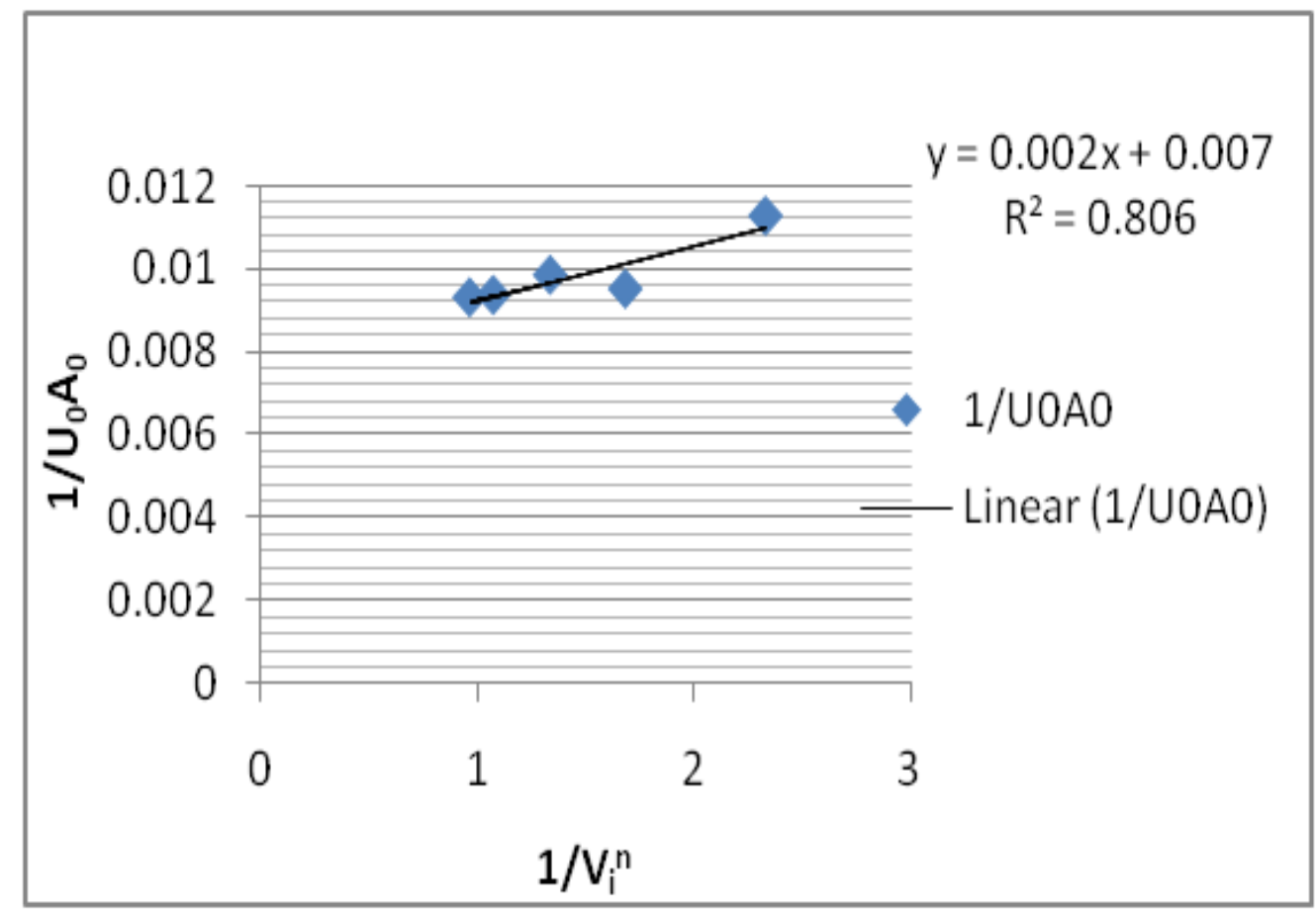

Fig-4: Actual Wilson Plot

From the equation the values of $c_{1}$ and $c_{2}$ are obtained.

$\mathrm{C}_{1}=0.007$

$\mathrm{C}_{2}=1 / \mathrm{m} \mathrm{x} \mathrm{A}$

$=1 / 0.002 \times 0.21$

$=2380.95$

\section{Step 10:}

Calculating convective heat transfer coefficients

$\mathrm{h}_{\mathrm{i}}=\mathrm{C}_{2} \times \mathrm{V}_{\mathrm{i}}^{\mathrm{n}}$

$\mathrm{h}_{\mathrm{i}}=\mathrm{C}_{2} \times \mathrm{V}_{\mathrm{i}}^{0.8}$

$=2380.95 \times(0.347334)^{0.8}$

$=1021.758 \mathrm{~W} / \mathrm{m}^{2} \mathrm{~K}$

$\mathrm{h}_{\mathrm{o}}$ is obtained from equation [14][15]

$\frac{1}{U_{o}}=\frac{A_{o}}{A_{i} h_{i}}+\frac{A_{o} \ln \left(\frac{d_{o}}{d_{i}}\right)}{2 \pi k l}+\frac{1}{h_{o}}$

$\mathrm{A}_{\mathrm{i}}=\pi \times \mathrm{d}_{\mathrm{i}} \times \mathrm{L}$

$=\pi \times 0.0117 \times 5.715$

$=0.21 \mathrm{~m}^{2}$

$\mathrm{h}_{\mathrm{o}}=1053.206 \mathrm{~W} / \mathrm{m}^{2} \mathrm{~K}$

\section{Step 11:}

Calculation of Reynolds Number

$\operatorname{Re}_{\mathrm{i}}=\frac{\rho_{\mathrm{h}} \mathrm{V}_{\mathrm{i}} \mathrm{d}_{\mathrm{i}}}{\mu}$

$\mathrm{Re}_{\mathrm{i}}=\frac{990.6875 \times 0.347334 \times 0.0117}{0.00062}$

$=6491.393$

$\operatorname{Re}_{\mathrm{o}}=\frac{\rho_{\mathrm{c}} \mathrm{V}_{\mathrm{o}} \mathrm{D}_{\mathrm{h}}}{\mu}$

$\operatorname{Re}_{\mathrm{o}}=\frac{994.629 \times 0.001579 \times 0.1078}{0.000753}$

$=224.7644$

Step 12:

Calculating Nusselt Number

$\mathrm{Nu}_{\mathrm{i}}=\frac{\mathrm{h}_{\mathrm{i}} \mathrm{d}_{\mathrm{i}}}{\mathrm{k}_{\mathrm{h}}}$

$\mathrm{Nu}_{\mathrm{i}}=\frac{1021.758 \times 0.0117}{0.6352}$ 


$$
=18.82
$$

$\mathrm{Nu}_{\mathrm{o}}=\frac{\mathrm{h}_{0} \mathrm{D}_{\mathrm{h}}}{\mathrm{k}_{\mathrm{c}}}$

$$
\begin{aligned}
\mathrm{Nu}_{\mathrm{o}} & =\frac{1053.206 \times 0.1078}{0.6216} \\
& =182.6505
\end{aligned}
$$

\section{Step 13:}

Pressure drop calculation

Calculation of friction factor using Reynolds Number

$f=\frac{7.2}{\operatorname{Re}_{i}^{0.5}}\left(\frac{d_{i}}{D_{c}}\right)^{0.25}$

On substituting value of di, Dc, and Re

$f=0.05366$
Now,

$\Delta \mathrm{P}=\frac{2 \mathrm{fL} \rho \mathrm{V}_{\mathrm{i}}^{2}}{\mathrm{~d}_{\mathrm{i}}}$

$\mathrm{L}=5.089 \mathrm{~m}$

$\rho=990.688 \mathrm{~kg} / \mathrm{m}^{3}$

$\mathrm{V}_{\mathrm{i}}=0.347334 \mathrm{~m} / \mathrm{s}$

$\mathrm{d}_{\mathrm{i}}=0.0117$

On substituting the values

$\Delta \mathrm{P}=5579.03 \mathrm{~N} / \mathrm{m}^{2}$

The pressure drop is in close agreement with experimental values hence it is acceptable.

\section{PARAMETRIC ANALYSIS}

The readings are taken on horizontally arranged counter flow helical coil heat exchanger and effect of flow rate on effectiveness, overall heat transfer coefficient, heat transfer and outlet hot water temperature is studied.

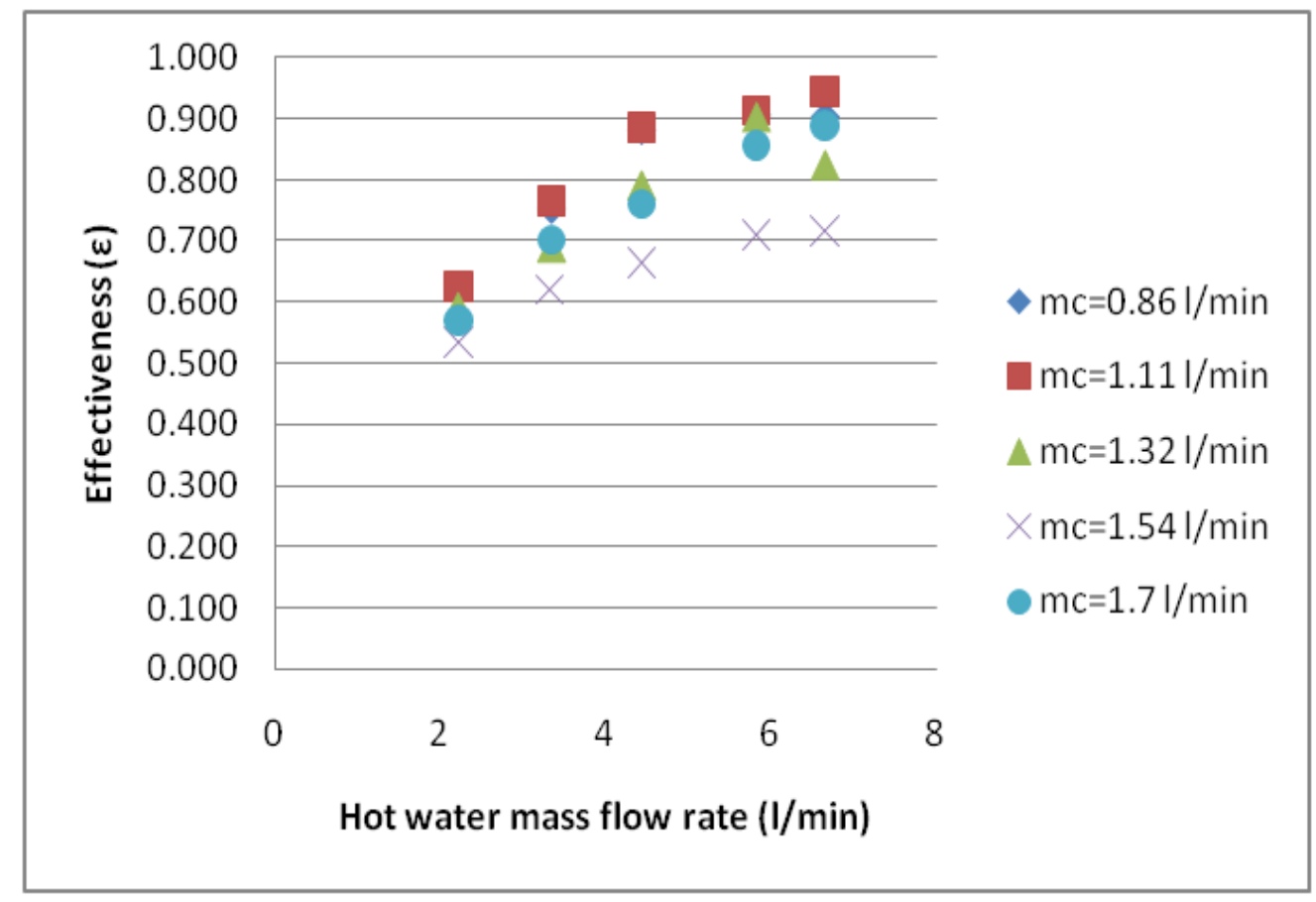

As the mass flow rate of hot water increases the effectiveness of heat exchanger increases for each corresponding mass flow rate of cold water when it is kept constant for set of five readings. 


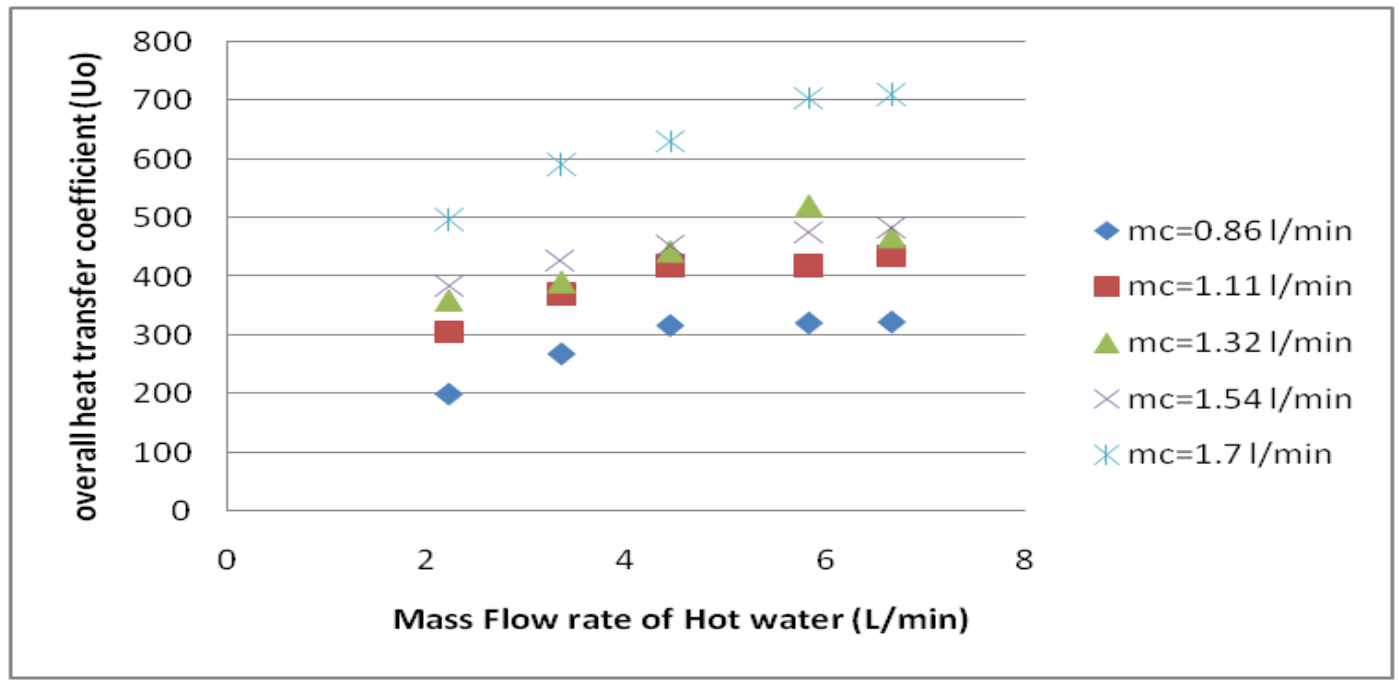

As the mass flow rate of hot water increases inside the tube the overall heat transfer coefficient increases for each corresponding mass flow rate of cold water when it is kept constant for set of five readings.

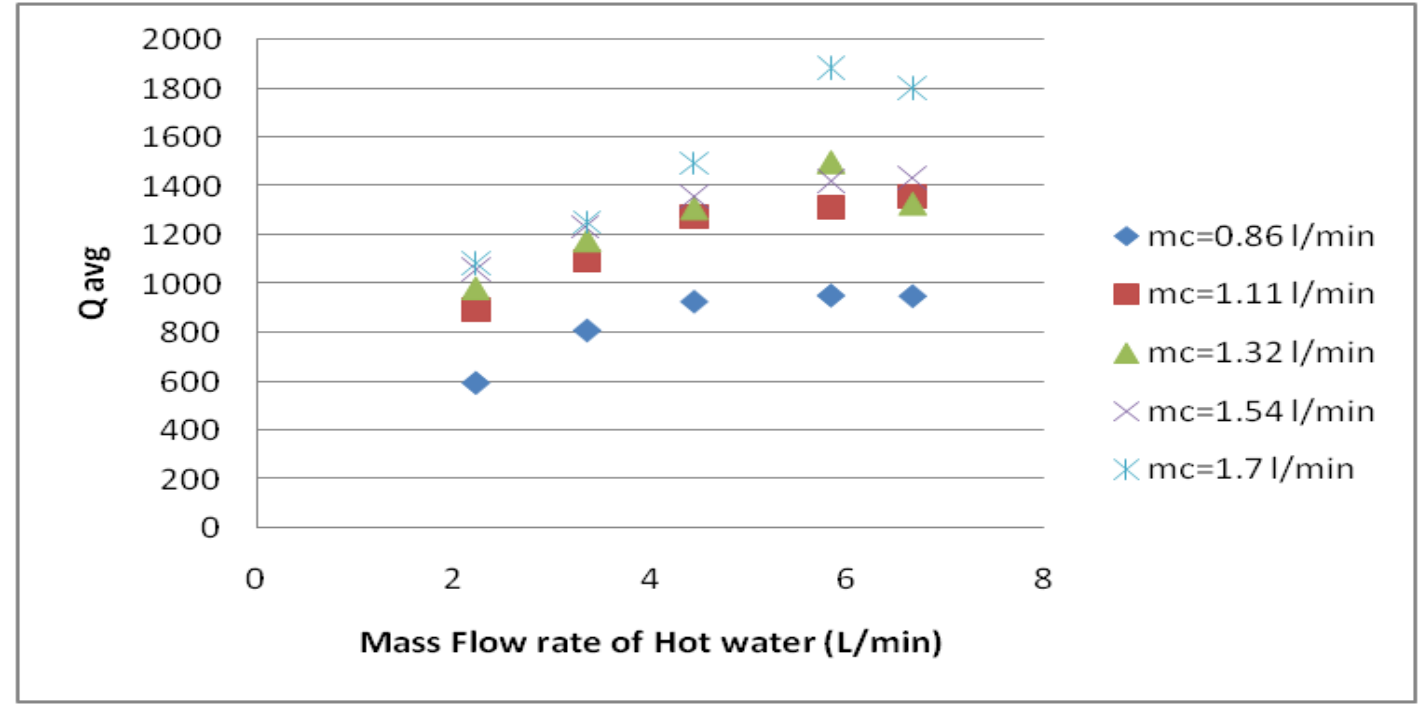

As the mass flow rate of hot water increases the average heat transfer rate increases gradually for each corresponding mass flow rate of cold water when it is kept constant for set of five readings.

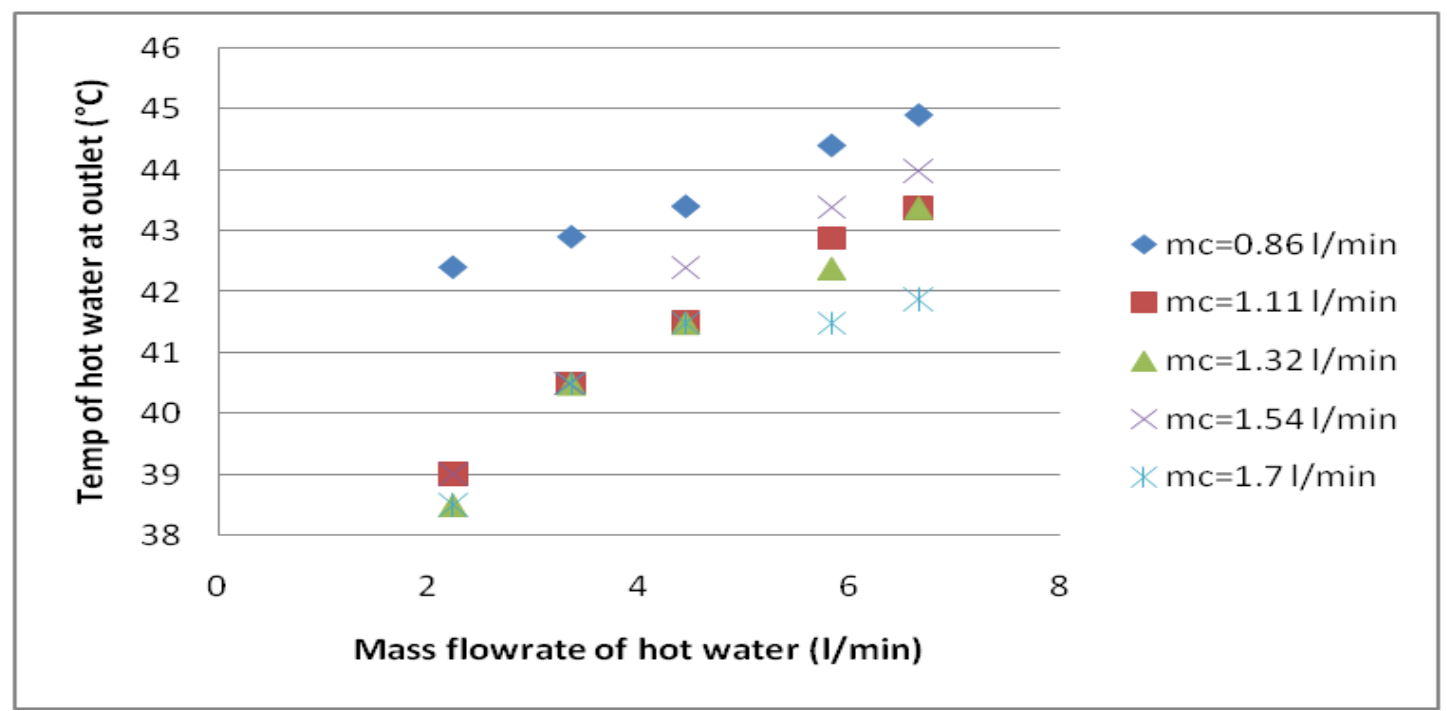


The temperature of hot water at outlet increases with increase in mass flow rate of hot water inside the tube. More amount of heat transfer takes place as mass flow rate of cold water on shell side increases.

\section{CONCLUSION}

The design and thermal evaluation of study under consideration is done and has following conclusions.

- The design procedure adopted gives sizing and rating analysis of helical coil heat exchanger and results are found in good agreement with the experimental results.

- By increasing mass flow rate of hot water the effectiveness increases at constant cold water mass flow rate.

- When mass flow rate of cold water is maintained at lower value the effectiveness is maximum but, when mass flow rates of cold water increases effectiveness decreases correspondingly.

- The overall heat transfer coefficient and Heat transfer rate increases with increase in mass flow rate of hot water.

- The overall heat transfer coefficient and heat transfer rate increases with minimum amount when mass flow rate of cold water is kept 0.86 whereas it is increases with maximum amount when mass flow rate is 1.71 .

- Also temperature of hot water at outlet increases with increase in hot water flow rate in the tube.

\section{REFERENCES}

[1] W.R. Dean, The Streamline Motion of Fluid in a Curved Pipe, Philosophical Magazine and Journal of Science, Series 7(5)( 1928) 673-695,.

[2] Dravid, A. N., Smith., K. A., Merrill, E.A., andBrian, P.L.T., (1971)—Effect of secondary fluid motion on laminar flow heat transfer in helically coiled tubes\|, AIChE Journal, Vol.17(5):1114-1122.

[3] Naphon, P., (2007)-Thermal performance and pressure drop of the helical-coil heat exchangers with and without helically crimped fins, Int.Communication of Heat Mass Tran, Vol.34 (3), pp.321-330.

[4] Naphon, P., and Wongwises, S., (2006) - A review of flow and heat transfer characteristics in curved tubes\|, Renew. Sust.Energ., Rev. 10, pp. 463-490.

[5] A.V. Kirpikov, Heat Transfer in Helically Coiled Pipes, Trudi. Moscov. Inst. Khim. Mashinojtrojenija, 12(1957), 43-56.

[6] C.M. White, Streamline Flow through Curved Pipes, Proceedings of the Royal Society of London, Series A 123(792)(1929) 645-663.

[7] R.A. Seban, and E.F. McLaughlin, Heat transfer in Tube Coils with Laminar and Turbulent Flow, International Journal of Heat and Mass Transfer, 6(1963) 387-395.

[8] D.G. Prabhanjan, G.S. Raghavan, T.J. Rennie, "Comparison of Heat Transfer Rates between a Straight Tube Heat Exchanger and a Helically
Coiled Heat Exchanger", 1nt. Comm. Heat Mass Transfer,29 (2) (2002) 185-191.

[9] R.K. Shah and D.P. Sekulic, Fundamentals of Heat Exchanger Design, John Wiley \& sons Inc., New York, 2003.

[10] R. K. Patil, B.W.Shende, P.K.Ghosh, “ Designing a helical coil Heat Exchanger”, Chemical Engineering Journal, December 1982.

[11] H. Shokouhmand, M.R. Salimpour, M.A. AkhavanBehabadi, Experimental Investigation of Shell and Coiled Tube Heat Exchangers Using Wilson Plots", International Communications in Heat and Mass Transfer, 35(2008) 84-92.

[12] A.K.Pandey,"Hydrodynamic characteristics of single phase fluid flow inside a helically coiled tube of small diameter.

[13] P.S. Purandare, M.M. Lele and R. Gupta, Parametric Analysis of Helical Coil Heat Exchanger, International Journal of Engineering Research \& Technology (IJERT), 1(8) (2012) 1-5.

[14] Salimpour M R, Heat Transfer Coefficients of Shell and Coiled Tube Heat Exchangers, Experimental Thermal and Fluid Science, 33,2009, 203 - 207.

[15] Jamshidi N, Farhadi M, Ganji D D \& Sedighi K, Experimental Analysis of Heat Transfer Enhancement in Shell and Helical Tube Heat Exchangers, Applied Thermal Engineering, 51, 2013,644 - 652 .

[16] Ghorbani N, Taherian H, Gorji M \& Mirgolbabaei $\mathrm{H}$, An Experimental Study of Thermal Performance of Shell-And-Coil Heat Exchangers, International Communications In Heat And Mass Transfer ,37, 2010, $775-781$.

[17] J. W. Rose, "Heat transfer coefficients, Wilson plots and accuracy of thermal measurements", experimental Thermal and Fluid Science, vol.28, pp. 77 - 86, 2004.

[18] Jose Fernandez-Seara, Francisco J Uhia ,Jaime Sieres, Antonio Campo, "A general review of the Wilson plot method and its modifications to determine convection coefficients in heat exchange devices", Applied Thermal Engineering, vol.27, pp. 2745 - 2757, Dec. 2007.

\section{BIOGRAPHIES}

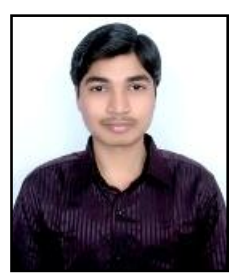

Amitkumar S. Puttewar, M.Tech Research Scholar, Department of Mechanical Engineering, Shri Ramdeobaba college of Engineering and Management,Nagpur.

amitputtewar48@gmail.com

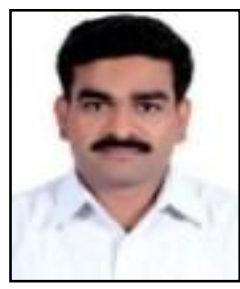

A.M. Andhare, Assistant Professor , Department of Mechanical Engineering, Shri Ramdeobaba college of Engineering and Management,Nagpur.

andhaream@rknec.edu 